\title{
Cibercultura
}

\section{A politização das imagens: da era mecânica às redes de comunicação digital}

The politicization of images: from the mechanical era to the digital communication networks

TARCISIO TORRES SILVA

Pontifícia Universidade Católica de Campinas - PUCCAMP.

<tarcisio.silva@puc-campinas.edu.br>

\section{RESUMO}

O potencial político das imagens produzidas por ativistas nas recentes manifestações sociais que afloram por todo o planeta pode ser melhor compreendido se o mesmo for localizado dentro de um campo de conhecimento específico pré-existente. Nesse sentido, nosso intuito é mostrar em que medida as imagens contemporâneas dialogam com estratégias políticas visuais já verificadas anteriormente e o que trazem de original para o debate atual das imagens digitais e o seu universo político. Em linhas gerais, nota-se que tais imagens se impõem pela urgência, o apelo emocional com ênfase no corpo e a expansão de significados adquiridos nas redes de comunicação digital, mostrando assim linhas de continuidade e ruptura com a tradição político-imagética que as cercam.

Palavras-chave: Políticas da imagem. Fotografia. Redes de comunicação digital.

\begin{abstract}
The political potential of images produced by activists in recent social protests that emerge all over the planet can be better comprehended if a pre-existent field of knowledge calls our attention. In this sense, our intention is to show to what extent contemporary images dialogue with visual political strategies previously verified and what original aspects they bring to the current debate about digital images and their political environment. Broadly speaking, it can be noticed that such images impose themselves by urgency, emotional appeal emphasizing the body and the extension of meaning acquired in digital communication networks, showing lines of continuality and disruption with the political-imagetic tradition surrounding them.
\end{abstract}

Keywords: Politics of image. Photography. Digital communication networks. 
— ntre o lento desenvolvimento da tecnologia da fotografia até meados do século XIX

¿e a produção das primeiras imagens que mostrarão eventos extremos de perto, foi preciso que a câmera ganhasse precisão, leveza e mobilidade. Essa possibilidade é essencial, pois as imagens deixaram de servir como registros passivos de eventos para se tornarem signos mais atuantes politicamente. É a mobilidade dos aparelhos que vai permitir com que os primeiros fotógrafos de guerra tornem-se mais atuantes dentro dos eventos que registram.

Entendemos que o que se produziu em termos imagéticos nesses eventos nos auxilia a entender alguns aspectos estéticos e políticos que geraram inúmeros debates sobre o impacto dessas imagens na sociedade. Pela primeira vez, leitores de jornais e revistas estavam sendo expostos às atrocidades da guerra como nunca antes. O debate político em torno dos eventos ganhou novas perspectivas no momento em que imagens de morte e destruição foram atreladas às narrativas textuais de guerra. Houve ainda, nesse momento histórico, uma clara influência do desenvolvimento tecnológico na produção de sentido de imagens indiciais. A possibilidade de se criar imagens mais "verdadeiras" contribuiu para o impacto afetivo e emocional das mesmas, o que por sua vez repercutiu na opinião global sobre os eventos em si mesmos.

\section{Fotografias de guerra}

Foi no período entre guerras que foram introduzidas no mercado máquinas fotográficas mais precisas, leves e portáteis, como a Leica. Esse aprimoramento fez com que as guerras subsequentes fossem registradas com imagens mais testemunhais, captadas por pessoas acompanhando os soldados no front ou que estavam muito próximas dos acontecimentos. A Guerra Civil Espanhola (1936-1939) foi a primeira guerra que contou com a cobertura de fotógrafos profissionais equipados com máquinas com essas características (Sontag, 2003, p. 22). 
Uma das fotos que exemplificam esse novo momento da fotografia é a do fotógrafo de guerra Robert Capa, Morte de um soldado republicano (Fig. 1) tirada durante a Guerra Civil Espanhola no momento exato em que um soldado recebe um tiro fatal. Apesar da ampla literatura que questiona a autenticidade da foto, se a tomarmos como verdadeira, motivo afinal pelo qual a foto é tão famosa, entendemos que a partir desse momento vai ser cada vez mais possível que testemunhas dos eventos, jornalistas ou não, registrem de perto as atrocidades da guerra.

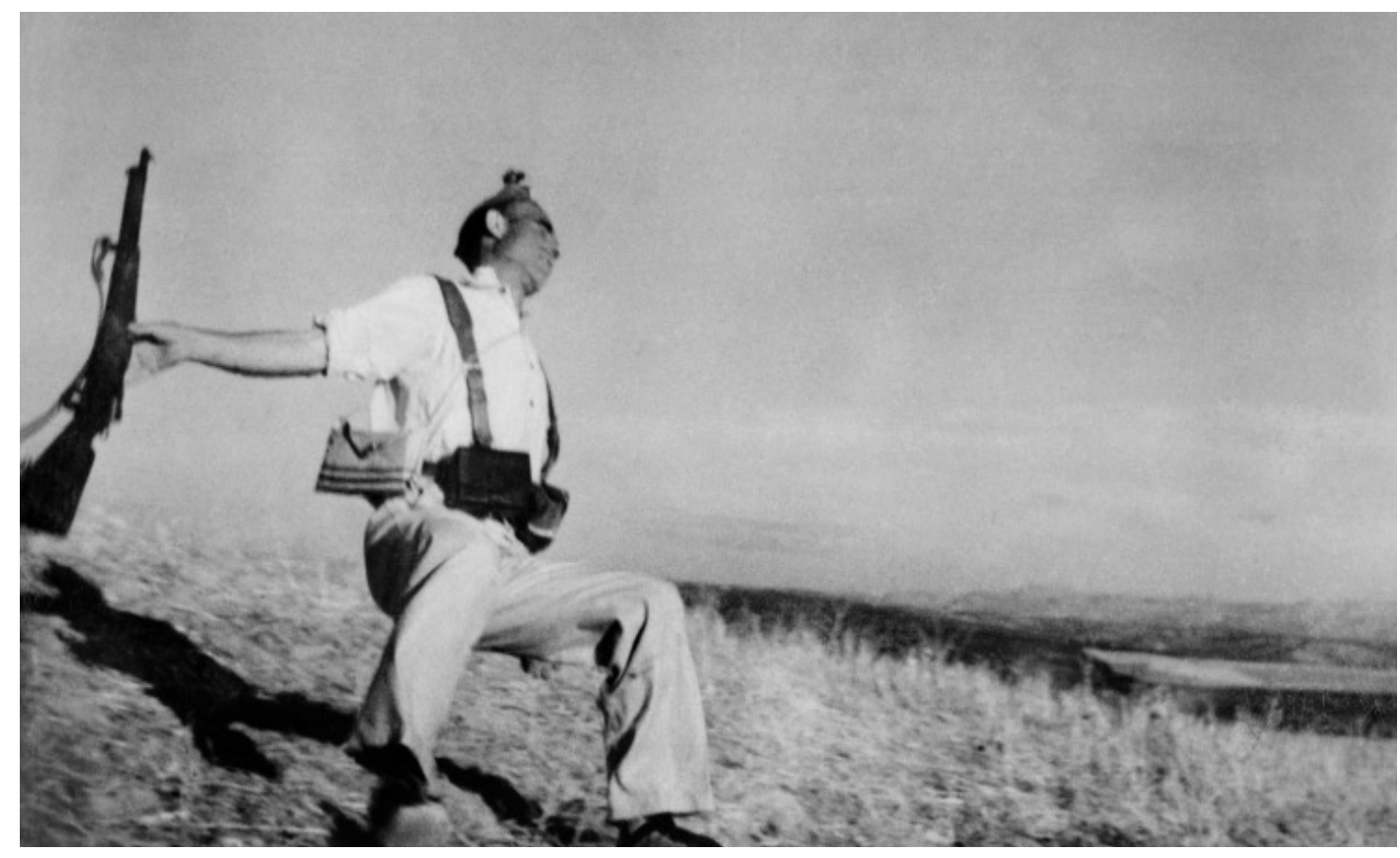

Figura 1 - "A Morte de um soldado republicano". Robert Capa, 1936. 
Em função desse aprimoramento tecnológico, a publicação das fotos de guerra em jornais e revista pelo mundo passou a ter maior impacto sobre as audiências. Pela primeira vez, as populações do mundo experimentaram a guerra sob um olhar mais próximo, a partir de fotos tiradas durante o calor dos acontecimentos. A Fig. 1, por exemplo, foi publicada no mesmo ano na revista francesa $V u$ e no ano seguinte na revista americana Life. Pouco tempo depois apareceria também em um jornal, o Paris-Soir (Sontag, 2003, p. 31).

Já na Segunda Guerra Mundial, há uma quantidade muito maior de registros, o que gerou por sua vez uma grande literatura voltada ao tema da produção de imagens como testemunhos de guerra. O mesmo Robert Capa é autor de uma ampla obra que mostra diversas perspectivas da guerra, seja do âmbito privado, registrando o cotidiano das pessoas durante a blitz em Londres, seja acompanhando a invasão dos aliados nas praias da Normandia, na França.

O fotógrafo em Ligeiramente fora de foco (Capa, 2010), seu livro autobiográfico que conta as estórias por trás de suas fotos de guerra, mostra como o fato de estar presente na cena dos acontecimentos é importante para a legitimação do seu trabalho. Um caso relatado no livro aconteceu durante a Segunda Guerra quando o fotógrafo estava na Inglaterra fotografando os trabalhos da aeronáutica no campo de pouso inglês de Chelveston, em 1942. Ele conta que um avião chegou depois de uma missão e de lá saíram quatro homens, dos quais dois estavam mortos, um praticamente sem vida e o piloto que estava bem. Ao ver o fotógrafo registrando a cena, o piloto teria dito: "Eram essas fotos que você estava esperando, fotógrafo?" (Capa, 2010, p. 65). A pergunta do piloto incomodou Capa, que achou que de fato parecia pouco legítimo ficar ali à espreita de uma tragédia anunciada. Refletindo sobre o que ocorreu, o fotógrafo disse: "Esse tipo de fotografia era para agentes funerários, e eu não gostava de ser um deles. Se eu tinha de participar do funeral, jurei, teria de participar da procissão" (Capa, 2010, p. 65). 
O relato de Capa valoriza o testemunho como parte intrínseca da qualidade de uma foto. Isso é particularmente visível nas fotos da Segunda Guerra e está ligado ao que estamos propondo discutir neste trabalho. Se a compararmos às guerras anteriores, não só haviam mais fotógrafos profissionais, como Capa cobrindo os conflitos, como era significativo o número de amadores com câmeras na mão. Tanto soldados alemães como os aliados registraram momentos de dor, morte, doença e destruição. Por estarem em locais de acesso difícil ou impossível à imprensa oficial, essas imagens hoje são um registro das atrocidades acometidas durante os anos da guerra.

Conhecidas mundialmente, as imagens da Segunda Guerra ainda chocam, dado o impacto que geram ao retratar o ser humano em estado de tamanha degradação. Emoções diversas são acionadas quando se entra em contato com essas imagens: dor, repugnância, desprezo, pena e o ódio. Por tal motivo, tais imagens são continuamente usadas sempre que se pretende contar a história da guerra por meio de imagens. Isso traz algumas análises fundamentais que nos serão úteis durante o desenvolvimento deste trabalho. Há em particular duas discussões que gostaríamos de mencionar com relação a essas imagens. Ambas tratam do olhar dos indivíduos que, através dos equipamentos ainda raros disponíveis na época, decidiram registrar o que testemunhavam durante os acontecimentos de guerra. São análises que politizam o olhar, ampliando seu significado, muitas vezes sobreposto e encoberto por interpretações recentes mais limitadas.

A primeira é a análise de Hüppauf (1997) que está interessado em reavaliar o papel dessas imagens, principalmente das geradas pelos soldados alemães, que são consideradas pela maioria das análises históricas como imagens que estão contaminadas pela ideologia do Partido Nacional Socialista Nazista. Imagens que colocam a superioridade alemã frente aos judeus. Porém, a crítica de Hüppauf sugere que se esse tipo de análise é levado em primeiro plano, desconsidera-se o olhar daquele que 
registra a imagem. Em última instância, deixa-se de lado o humano por trás da câmera, considerando-se apenas uma ideologia que o estaria dominando completamente.

A suspeita de Hüppauf tem início quando este mostra que diversas testemunhas de guerras que registraram imagens dos acontecimentos esconderam as fotos de todos da família e até de si mesmos, mantendo-as em lugares secretos por anos. $\mathrm{O}$ aparecimento das coleções mostrou o motivo da vergonha de seus donos originais e a intensidade das imagens reveladas. Para Hüppauf, este fato denuncia uma espécie de relação do indivíduo com as imagens que registrou. As imagens, de fato, poderiam incriminar seu dono por revelar os atos que presenciou como testemunha ocular, em um ato similar do que veio a ser chamada de "estratégia de invisibilidade" (usada pelos nazistas para tentar esconder seus crimes ao final da guerra por meio da destruição das evidências).

Porém, o argumento do autor se contrapõe à condenação direta daquele que registra essas imagens. Hüppauf fala de um olhar neutralizado do homem por trás da câmera, que está sujeito a duas emoções distintas. Este homem tem medo da memória o trair e por isso registra o que vê à sua frente, e ao mesmo tempo tem esperança de que o registro o auxilie a guiar sua memória no futuro. A combinação de medo e esperança seria responsável, na opinião do autor, por uma neutralização de perspectiva. Como consequência, o sujeito que registra consegue "esconder-se" atrás da objetiva da câmera num processo de "de-subjetivação". O olhar torna-se um olhar amoral e vazio e, por isso, mais racional sobre aquilo que registra através da câmera. Nas palavras do autor:

$O$ desejo de resguardar um espaço para si que se mantém intacto perante os horrores documentados cria a necessidade de esvaziar o olhar dessensibilizando-o e descorporificando-o. Dor e agonia são relegados ao outro lado da divisão binária e sujeitos a um olhar de abstração."1

(Hüppauf, 1997, p. 32) 
Assim, o autor entende que por meio do aparelho tecnológico (a câmera) acontece esse processo que desprende o olhar do "eu". É como se a câmera funcionasse como uma espécie de escudo que protegeria a identidade do "eu" das atrocidades que o olhar testemunha, produzindo assim imagens de "ordem espacial inequívoca", de "perspectiva inquestionável" e ao mesmo tempo "esvaziadas de valores" (Hüppauf, 1997, p. 31).

A outra discussão a respeito do olhar das imagens da Segunda Guerra Mundial que gostaríamos de destacar aqui é de Guerin (2004). A autora mostra de que forma fragmentos de vídeos amadores da Segunda Guerra são usados para construir narrativas que não necessariamente condizem com o olhar daquele que os produziu. A autora refere-se à reutilização dos fragmentos pela rede de televisão britânica BBC ao produzir o filme The Third Reich in Colour (Michael Kloft, 2001). Ela mostra que seus produtores, ao invés de procurarem estender o significado desses filmes, optaram por um estreitamento da narrativa ao induzir o espectador a uma interpretação que reforça a ideologia nazista que supostamente estaria no centro da produção daquelas imagens. Por meio de um detalhamento de três fragmentos de filme feitos no gueto de Varsóvia, que mostram a circulação de cidadãos, a movimentação de um mercado e crianças pedindo esmolas, a autora mostra que inúmeras perguntas que poderiam ser feitas sobre o olhar daquele que filma - sua curiosidade sobre os tipos que vê, suas indumentárias religiosas, o cotidiano do gueto ou que pensariam as pessoas que ignoravam as crianças famintas estiradas pelas ruas - deixam de ser feitas para reforçar uma narrativa já conhecida por todos. Ao fazer isso, os produtores da $B B C$ ignoram aspectos estéticos da imagem que dariam a chance para o espectador olhar os atributos dessas imagens de outra forma, se, no entanto, não fossem suprimidos por meio de uma "narrativa autoritária". 
Para a autora, os fragmentos de vídeo amador despertam o medo por propor uma outra perspectiva de entendimento do evento histórico. Assim, para o olhar britânico dos produtos da $B B C$ é melhor suprimir seu potencial estético do que dar vazão a outras possibilidades, como a de repensar a responsabilidade britânica na guerra. Para Guerin,

[...] os filmes coloridos amadores tornam-se os locais de medo e ansiedade deslocados. As imagens em si são esquecidas, sua importância é ignorada, assim como tudo o que temos para aprender com elas. De maneira similar, seu alcance para além da ideologia nazista é tratado como irrelevante."2

(2004, on-line)

O exemplo da autora é significativo para pensarmos como uma mesma imagem pode ser reconduzida a significados diferentes, dependendo da narrativa em que é inserida. Nesse processo, elementos estéticos que possibilitariam interpretações políticas mais livres de um determinado objeto são suprimidos para dar lugar a narrativas previamente escolhidas. A má apropriação dos fragmentos de vídeo fragilizam assim os elementos históricos e estéticos que eles carregam.

Os exemplos acima ligados às imagens amadoras da Segunda Guerra Mundial mostram particularidades que estão atreladas aos seus autores. Em todos os casos, há a desvinculação das imagens de uma narrativa predominante ligada ao Estado alemão. Isso é possível através de duas formas. Nas reflexões propostas por Hüppauf e Guerin, a politização dessas imagens está na neutralização do olhar do sujeito que 
registra. Em Hüppauf, essa neutralização é uma explicação para entender a condição a que está submetido o sujeito que testemunha os horrores da guerra e uma espécie de defesa psíquica que o motiva ao registro ao mesmo tempo em que se sente distante daquilo que vê. Em Guerin, temos o convite ao esforço de entendermos documentos históricos à parte de toda a carga ideológica que carregam, ainda mais quando são constantemente reutilizados para reforçar narrativas já existentes. Ao procurarmos entender as imagens a partir do que elas significam em si mesmas, politizamos o olhar para refletirmos sobre outras possibilidades de interpretação até então não consideradas.

Assim, entendemos que a politização das imagens mecânicas no sentido que aqui expomos já é verificada, desde seus primórdios, ao olhar subjetivo de quem registra, às possibilidades de renarrativização das imagens e do potencial estético da imagem amadora por trazer em si algo ligado à identificação do olhar e ao cotidiano do espectador. Soma-se a isso o elemento testemunhal, que insere realismo, que torna o fato mais palpável, presente tanto nas imagens profissionais como amadoras, a depender dos motivos retratados.

Feitas essas considerações sobre a politização das imagens mecânicas, gostaríamos agora de dar andamento à nossa argumentação mostrando que os elementos políticos da imagem apontados até esse momento permanecem presentes no debate contemporâneo, ao mesmo tempo em que outros elementos são adicionados à discussão. Como faremos um salto histórico muito grande, vale lembrar que, do ponto de vista estético e político, alguns aprimoramentos tecnológicos tiveram destaque nos registros de conflitos mais recentes. A Guerra do Vietnã (1955-1975) foi a primeira guerra com cobertura pela TV (Sontag, 2003, p. 57). Mais recentemente, as imagens noturnas em vídeo foi o grande instrumento de análise das imagens divulgadas da Guerra do Golfo (1991). O céu iluminado da chamada "tecnoguerra" (Sontag, 2003, p. 57), 
mostrava a superioridade norte-americana sobre o inimigo. Finalmente, como último recurso tecnológico que veio a resignificar consideravelmente o campo das imagens foi sua passagem do mecânico para o digital.

\section{Imagens contemporâneas, continuidades do olhar e novas perspectivas}

A passagem do século XX para o século XXI coincide com a mobilidade de equipamentos portáteis de registros de imagens e com a grande evolução, principalmente, dos equipamentos em vídeo, que ficaram menores, mais baratos e mais eficazes. Apesar de mais evidente no final da primeira década do século XXI, com a evolução dos aparelhos de telefonia móvel, os aparelhos de registro de imagens já acompanhavam as pessoas em suas experiências cotidianas como amadores ou profissionais. Isso é claramente notado nas imagens dos atentados ao World Trade Center (WTC), em Nova York, em 2001, em que uma profusão de imagens foi gerada pelas testemunhas presentes no local. Em termos evolutivos, há alguns aspectos atrelados a essas imagens que merecem ser destacados.

Em primeiro lugar, muitas pessoas nas ruas portavam equipamentos que as possibilitaram registrar os eventos. Há muitos vídeos feitos pelos cinegrafistas dos canais de TV de todo o mundo, mas também há registros de amadores, entre eles habitantes de prédios próximos, turistas, bombeiros, policiais e militares. Essa multiplicidade de olhares é o que compõem a memória imagética do evento como o conhecemos hoje, ou seja, um evento amplamente registrado, sob diferentes ângulos e perspectivas.

Com relação especificamente a essas imagens, cabe uma diferenciação. Passada mais de uma década, percebe-se que as fotografias que hoje simbolizam alguns momentos essenciais dos ataques foram, em sua maioria, tiradas por profissionais com 
equipamentos de excelente nitidez. Foram também as fotografias que mais circularam pela grande mídia na época. Isso fica evidente pelo próprio registro das imagens, com os créditos às agências de notícias. Isso mostra que o olhar profissional, a qualidade do equipamento e o resultado estético fizeram com que tais imagens fossem selecionadas para compor esta "simbologia essencial" fotográfica do evento.

Por outro lado, se olharmos para os vídeos que foram feitos, esse marco divisório entre profissional/amador não parece tão claro. Um estudo mais aprofundado sobre esse tema poderia ser feito, mas ao navegarmos por sites de compartilhamento de vídeos e outros que armazenam um grande contingente de material, é nítida a presença de muitos vídeos caseiros feitos por testemunhas, profissionais do jornalismo ou amadores $^{3}$.

Além disso, vale notar que o 11 de setembro foi um acontecimento mundial de ampla cobertura midiática em que se verificou, talvez pela primeira vez, a presença mais evidente da internet e das redes de comunicação digital. Isso trouxe como consequência pelo menos duas coisas. A primeira é a significativa cobertura da internet como mídia nessa época. Assim, se a entendermos como uma mídia de consumo mais individual, dada as características do próprio meio (navegação, interatividade, imersão do usuário) há uma nova instância a ser considerada no consumo das imagens do evento. Além de um olhar subjetivo do sujeito com a tela e, consequentemente, sob aquilo que lhe chama atenção. É claro que esse consumo não é isolado, já que a mídia de massa ainda foi extremamente importante para a cobertura e disseminação das primeiras imagens do evento, mas é um novo elemento a ser considerado.

O outro aspecto a ser analisado está ligado aos conteúdos produzidos. O olhar do sujeito diante daquelas imagens identifica-se, de certa maneira, com o ponto de vista de alguns dos conteúdos produzidos no evento. Os vídeos trêmulos registrados pelas testemunhas anônimas foram capazes, sob nosso ponto de vista, de nivelar as imagens 
dos atentados ao patamar do sujeito espectador. As qualidades estéticas dos vídeos (ou a falta delas), com seu amadorismo e ponto de vista testemunhal, aproximam a recepção do espectador. Além disso, a rapidez das redes de comunicação proporcionou maior velocidade na propagação dessas imagens que por sua vez traziam um novo elemento ao caráter espetacular dos eventos. Eram imagens estonteantes, mas ao mesmo tempo muito próximas do espectador por esses elementos que aqui apontamos.

O evento é emblemático não apenas do ponto de vista geopolítico, em que uma nova divisão do mundo estaria se configurando, mas também pelo fato de ter sido um evento efetivamente midiático. Os alvos e as formas de ataque já pressupunham o registro imagético que tiveram os eventos. Os terroristas sabiam que os atentados seriam filmados e reproduzidos em exaustão por todo o mundo. Em seu argumento sobre as consequências imagético-políticas do evento, Henry Giroux irá nos dizer que:

A marca distintiva dos ataques horríveis e pavorosos às Torres Gêmeas e ao Pentágono é que eles foram designados a serem visíveis, designados a serem espetaculares. Eles não só ostentam uma estranha similaridade com os filmes de desastre hollywoodianos com violência saturada, mas são de forma similar são adequados para - destinados a - reexibição infinita nos noticiários noturnos, trazendo um fim para as liberdades democráticas com bênçãos de democracia."4

(Giroux, 2006, p. 29)

Do ponto de vista de nossa argumentação neste trabalho, poderíamos agora nos perguntar se há nos registros dos atentados ao WTC os mesmos elementos 
existentes nas imagens das testemunhas de guerra apontadas no início desse capítulo. Quais atributos daquelas imagens permanecem em registros contemporâneos do indescritível? Se verificados assim, seus efeitos permanecem os mesmos?

Podemos afirmar que boa parte daqueles elementos ainda acompanham as imagens das testemunhas dos atentados em Nova York. Os personagens continuam nas ruas, apenas as formas de registro é que ganharam em agilidade e definição. Ainda é possível observar no grande material produzido imagens que tratam de um testemunho, que propõem o ponto de vista subjetivo de quem faz escolhas nos registros e de quem observa o inacreditável, principalmente nos vídeos em que a intensidade é mostrada em toda a sua magnitude.

As imagens do 11 de setembro também surpreendem pelo caráter de eventualidade que muitos dos curtos filmes têm. Várias pessoas foram pegas de surpresa em suas filmagens, demonstrando isso claramente em suas reações quando, ao filmar a primeira torre em chamas, foram surpreendidas por outra colisão de avião na outra torre. Numa espécie de neutralização do olhar, como proposto por Hüppauf (1997), as pessoas nas ruas, jornalistas, bombeiros e policiais, mantiveram as câmeras ligadas, registrando a dor, a morte e o sofrimento dos que ainda continuavam presos nas torres. Em um dos registros mais impressionantes ${ }^{5}$, o cinegrafista faz o caminho inverso das pessoas que fugiam dos arredores dos prédios antes do primeiro desmoronamento. Ele caminha em direção a eles, entra em um dos prédios, filma as instalações internas e os arredores já quase vazios. Nas imagens, o olhar humanizado desse cinegrafista é evidente. Ao invés de buscar ângulos monumentais dos prédios em chamas, o cinegrafista ocupase em registrar as faces dos bombeiros entrando nos prédios, de uma funcionária do WTC que os recebe, das bancas de frutas e outros negócios em torno dos prédios vazios, uns óculos abandonados no chão, etc. Ao fundo, a música ambiente da praça do WTC permanece ativa, num estranho fragmento de paz momentos antes da queda das torres. 
Nas ruas, percebe-se em algumas das imagens a mesma curiosidade humanizada que é manifestada pelo registro dos passantes. Desconsideradas quaisquer relações políticas ou étnicas que tal comparação poderia criar, e considerando-os apenas como personagens, o que prendeu a atenção dos cinegrafistas em Nova York foi certa curiosidade pelos transeuntes na situação em que se encontravam, como aquela que atraiu o olhar daqueles que filmavam os judeus no gueto. Os personagens eram executivos que, após o colapso das torres, foram cobertos por uma camada de poeira que os tornou irreconhecíveis. Um tipo de despersonificação que atraiu a atenção dos inúmeros fotógrafos, amadores ou não, ali presentes. Esse interesse pelo humano num momento extremo como foi o dos atentados em que, por exemplo, optou-se por registrar a face das pessoas diante do terror do que o terror em si, novamente nos lembra àquele olhar do observador do gueto, atento aos sinais humanos frente a enormes atrocidades.

Soma-se a isso o rápida transformação em ícones de diversas imagens do 11 de setembro, num processo de produção em que, intencionalmente ou não, foram reutilizadas pela imprensa internacional justamente por carregarem em si elementos reconhecíveis de outros momentos políticos extremos presentes na memória afetiva das pessoas por meio de outras imagens. Entre os diversos exemplos explorados nesse sentido, há uma fotografia em que os bombeiros de Nova York fincam uma bandeira americana sobre os destroços do WTC A imagem lembra a famosa foto tirada por Joe Rosenthal em Iwo Jima, no Japão, em 1945, quando soldados americanos executavam a mesma tarefa naquelas terras para celebrar sua vitória ${ }^{6}$. A identificação dos paralelos entre as imagens e os benefícios de se produzir efeitos equiparando-as foi rapidamente percebida pela mídia internacional e logo esta foto tornou-se uma das mais utilizadas pelos editores de jornais e revistas de todo o mundo. 
Podemos dizer que essa rápida reutilização das imagens, recontextualizando-as e fazendo referências a outros campos de significação, é um atributo que é intensificado com a digitalização das imagens. Veremos em seguida nesse trabalho como a utilização e reutilização das imagens contemporâneas serão ainda mais intensificadas, ao ponto de se perder a referência inicial. Com isso, discursos serão ao mesmo tempo politizados e despolitizados, a depender do uso que se faz das imagens.

Como apresentamos até agora, é possível fazer aproximações que nos ajudam a ler as imagens políticas no mundo contemporâneo com o auxílio das análises de imagens históricas que foram apresentadas no início desse capítulo. Porém, nosso intuito é ir além dessas aproximações, pois entendemos que o cenário "tecno-estéticopolítico" em que localizaremos as imagens nesse trabalho tem em si mesmo uma complexidade que deve ser analisada em profundidade. Dentro do que expusemos até aqui, já fomos minimamente

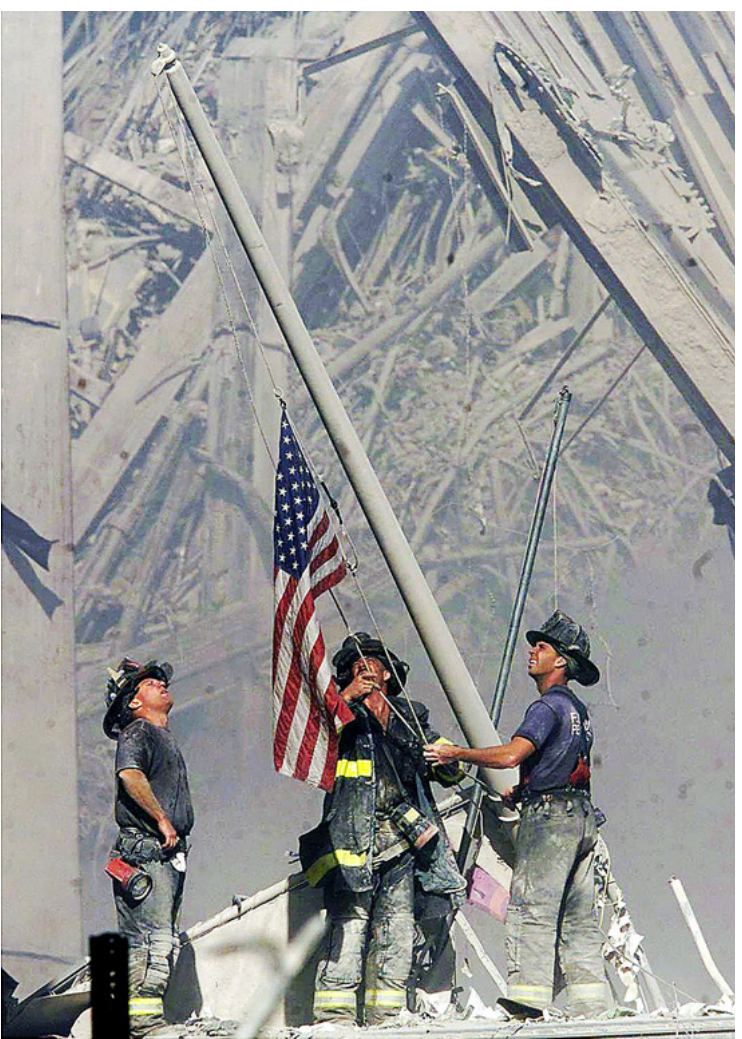

Figura 2 - Bombeiros hasteando a bandeira americana nos escombros do WTC. indicando em que níveis estão essas complexidades ligadas à imagem política contemporânea. No trecho final que se segue mostraremos que outros novos elementos devem ser considerados de forma a problematizar as imagens políticas contemporâneas com foco no testemunho e no amador. 


\section{O espetáculo do terror e a biopolítica das imagens contemporâneas}

Uma das leituras possíveis de recontextualização das imagens políticas na atualidade é proposta por Giroux (2007). Para tanto, o autor vai direcionar sua análise para as imagens ligadas ao terror, à violência e ao sofrimento, notando que há diferenças na forma como esses elementos são explorados a depender do contexto histórico. Em sua interpretação, essas imagens podem ser lidas em dois momentos distintos a partir da sociedade de massas.

O primeiro momento é chamado pelo autor de "terror do espetáculo", evidenciado nas práticas fascistas e na sociedade de consumo. Nesses períodos, prevaleceu um senso de unidade que foi criado com o auxílio de imagens que exploravam a politização do coletivo ao invés da explorar a guerra em si mesma. A estratégia, como sabemos, foi altamente praticada pelos fascistas que promoviam a estetização da violência por meio da valorização do militarismo, da grandiosidade dos desfiles oficiais e da glorificação da raça ariana como símbolo de perfeição.

Além da estética nazista, localizam-se também na categoria de "terror do espetáculo" as imagens da sociedade de consumo. Inspirado pelas ideias de Debord (1997), Giroux (2007) afirma que nesse período prevaleceu o interesse do controle das massas por meio de imagens. Estas funcionariam como disseminadoras do senso comum compartilhado e de um simulacro que contribuiriam para a criação de um cenário homogêneo, diretamente ligado aos interesses do Estado e do mercado.

O segundo momento é chamado por Giroux de "espetáculo do terrorismo". Nessa nova fase, as relações sociais não estariam mais sendo construídas a partir de um senso de unidade, mas através de sensações mais individuais como o medo e o terror. O espetáculo do terrorismo é também mostrado e explorado por imagens, tratando-se 
de um recurso usado (tanto pelos governos como pela grande mídia) como forma de fazer política por meio do medo e da morte. Ao mesmo tempo, os inimigos do Estado, os terroristas, usam do mesmo recurso em vídeos de degolamentos e de ataques de homens-bomba.

Essa mudança na maneira como o terror e a violência aparecem na nova fase é explicada por Giroux de duas maneiras. A primeira está ligada ao desenvolvimento tecnológico de produção e distribuição de imagens, com a introdução da internet e outros aparelhos de captura e reprodução, por exemplo. Como consequência desse desenvolvimento intitulado pelo autor como "segunda era da mídia", há uma descentralização da produção e transmissão de imagens, o que gera o surgimento de novas vozes no processo comunicacional global.

A segunda explicação está vinculada à mudança do papel do Estado na sociedade contemporânea, que deixa de executar tarefas em múltiplas instâncias de poder para concentrar-se em ações de segurança. A dinâmica do capitalismo global faz com que o mercado ganhe força nas relações de poder, o que por sua vez limita a ação estatal. Como reação a esse cenário, o Estado responde por meio de políticas de segurança. Segundo Giroux:

Os salvaguardas econômicos, políticos e sociais da modernidade, ainda que restritos, juntamente com as coordenadas espaciais $e$ temporais da experiência, explodiram na "segunda era da mídia" como a espetacularização do medo e a militarização crescente do cotidiano que se tornaram as experiências culturais principais de formação de identidades, valores e relações sociais."7

(Giroux, 2007, p. 28) 
Na interpretação de Giroux, a estratégia governamental para gerar controle está na exploração do real, ante o simulacro estetizado do mercado. Isso será feito não por meio do incentivo à compaixão pelo outro, mas alimentando o medo do indivíduo que reflete no preservar-se a si mesmo. Além disso, há também para o autor uma crise na subjetividade contemporânea que atravessa uma falta generalizada de sentido. É por meio da tentativa de preencher essa lacuna que significados como o medo e a insegurança são articulados como estratégias do poder estatal.

Mas qual a forma dessas emoções no que diz respeito às imagens? Giroux entende que os sentimentos de medo, sofrimento, humilhação, degradação e morte estão atrelados a uma noção social retrógrada que faz com que haja o laço social esperado no espetáculo do terrorismo. É uma noção de cultura de medos compartilhados ao invés de responsabilidades compartilhadas (Giroux, 2007, p. 30).

Porém, como foi observado, o cenário do "espetáculo do terrorismo" é mais complexo do que na sociedade de massa. Isso se dá em função da multiplicidade de vozes que estão em ação nesse contexto. Da mesma forma que o governo e a mídia oficial utilizam-se das noções de terror aqui expostas, do outro lado há também uma série de grupos descentralizados, ativistas e organizações terroristas que irão explorar as mesmas estratégias para dar visibilidade às suas intenções, combatendo assim com a mesma moeda as estratégias oficiais.

Um dos casos que melhor representam esse cenário dúbio das imagens contemporâneas do terror é o da prisão de Abu Ghraib no oeste de Bagdá, onde presos iraquianos foram fotografados por soldados norte-americanos em situações humilhantes no ano de 2004. O fato é referenciado por diversos acadêmicos que perceberam ali a conotação política das imagens amadoras. O caso ganhou dimensões que se estenderam para uma problematização bastante séria que questionou a legitimidade estadunidense para com suas decisões políticas de segurança internacional. 
A invasão dos EUA ao Iraque já era na época questionada globalmente. Essa dúvida ficou ainda maior com a transmissão das fotos dos soldados no programa da CBS 60 Minutes II, em abril de 2004, dando início a uma circulação interminável das imagens divulgadas inicialmente em círculos fechados. Andén-Papadopoulos (2008) mostra em seu artigo que essas imagens amadoras, feitas despretensiosamente, foram alvo de uma resignificação criada a partir de discursos que iriam tanto direcionar suas intenções para o âmbito privado dos sujeitos que as produziram como inverter os significados inicialmente estabelecidos, politizando as imagens tanto local quanto globalmente.

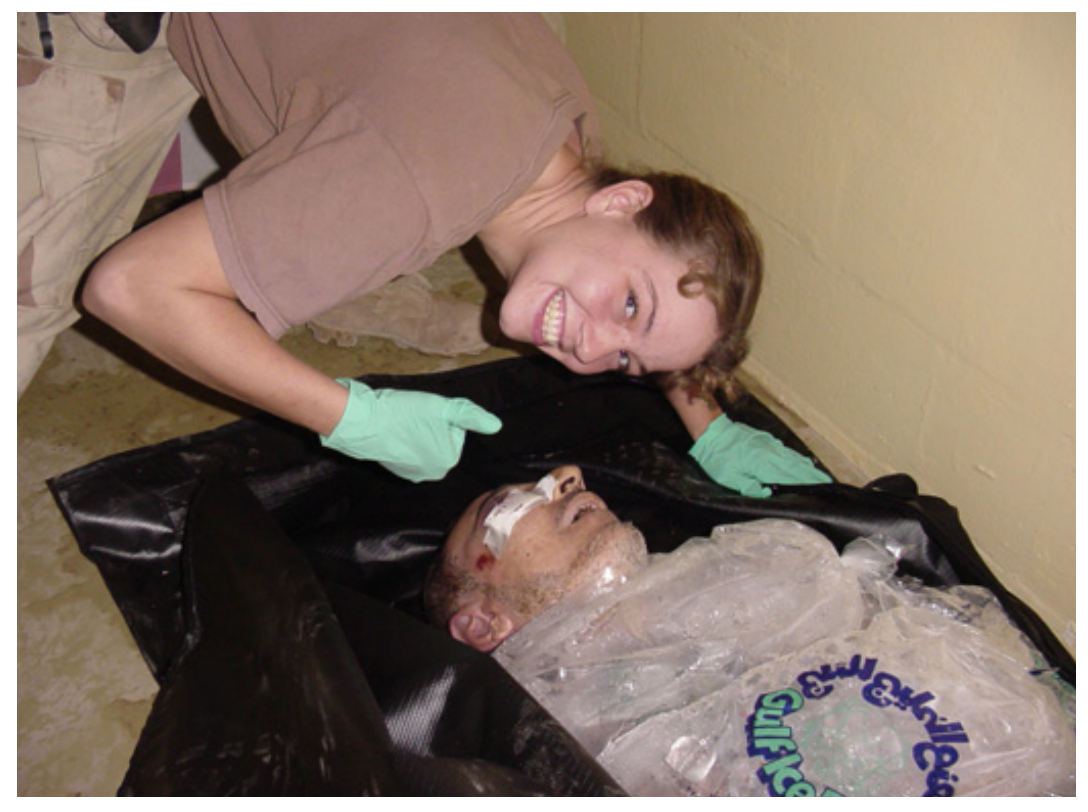

Figura 3 - Soldado Sabrina Harman em foto com um dos prisioneiros mortos em Abu Ghraib.

Fonte: <http://graphics8.nytimes.com/images/ blogs/morris/posts/27morris_2728_C_11.jpg> (01/10/2013). 
Andén-Papadoulos mostra que quando percebe o poder político daquelas imagens, o governo cria um discurso que tenta culpar indivíduos, isentando de responsabilidade a instituição do Exército Americano. Nesse ponto de vista, as imagens representariam os atos de sujeitos pouco responsáveis que deveriam ser punidos por isso. Essa fala minimizaria o impacto das imagens que implicitamente acusavam o comportamento do exército no Iraque como inadequado, não se tratando apenas de atos de indivíduos irresponsáveis. Em contrapartida, autora mostra que a circulação das imagens em diversas mídias provocou também uma resignificação de sua intenção inicial, entre as quais poderíamos elencar a humilhação dos presos, sua desumanização ou ainda a demonstração da superioridade americana. As imagens foram reapropriadas e ganharam sentidos políticos. Reproduzidas em pôsteres, murais, publicidade, quadrinhos, arte e em sites (Andén-Papadoulos, 2008, p. 6), essas imagens amadoras foram recontextualizadas em diversos estratos da cultura.

A autora defende que imagens provocativas como essas têm o poder de criar novas narrativas, ainda mais quando adquirem características icônicas como as que foram observadas nesse caso. Com referência a esse assunto, argumenta que:

Imagens que contradizem ou que rompem uma estrutura de discurso dominante podem ter um impacto considerável, se não diretamente sobre a política e o fazer político, então mais ainda sobre a imaginação popular e a consciência histórica. Imagens icônicas da mídia noticiosa são notavelmente migratórias, sendo com frequência apropriadas e recirculadas instantaneamente na cultura geral."8

(Andés-Papadopoulos, 2008, p. 6) 
O exemplo mostra que houve uma politização efetiva de múltiplas vozes a partir das imagens. Isso faz com que a prática privada dos soldados ganhe uma politização de domínio público, com a apropriação e recirculação em discursos locais e globais. Num claro exemplo de inversão do discurso, temos o uso das imagens como bandeira à anti-ocupação do Iraque, o oposto do desejado pelos soldados com suas fotos.

A preocupação da autora com relação às imagens por ela estudadas está no questionamento de como elas são capazes de influenciar a consciência política das pessoas. Além dos excelentes apontamentos colocados pela autora, que destaca o poder de circulação e resignificação dessas imagens, chamaríamos a atenção também para dois outros elementos significativos das imagens citadas.

Em primeiro lugar, pontuamos as características de uma estética extremamente amadora das fotos. É desconcertante observar soldados sorridentes, com o polegar para o alto, fazendo o sinal de "joia", tendo atrás de si prisioneiros mortos, algemados ou encapuzados. É como se o cenário de uma foto de álbum familiar fosse substituído erroneamente por um outro, completamente descontextualizado. Apesar desse desconcerto inicial, é a mesma estética amadora que nos provoca identificação. Justamente por trazer na mesma imagem algo que nos é tão próximo (a opção estética da pose), com algo que nos é tão distante (a imagem da guerra, do preso, das algemas), as fotografias captam a atenção do espectador, seja qual for sua localização geográfica no globo e a forma como irá interpretar tais imagens.

Outro aspecto que nos parece bastante importante para entender o impacto gerado por essas imagens, o que por consequência criou a infinita reprodução e reapropriação das mesmas, está no fato de que todas elas politizam o corpo de alguma forma. Humilhado, despersonalizado ou ridicularizado, parece ser o corpo ali presente que reforça o elemento "real" das fotos. Novamente temos presentes as emoções articuladas em função de imagens de dor e sofrimento, o que nos sugere que o exemplo aqui dado 
está relacionado com o argumento já apresentado de Giroux (2007), sobre o fato de estarmos vivenciando hoje o "espetáculo do terrorismo". Nesse jogo, atuam forças antagônicas em disputa por relações de poder que usam com estratégia a articulação de emoções extremas, como o medo, o terror e a morte.

\section{Conclusão}

Por meio das análises realizadas, podemos afirmar que a imagem do corpo é um elemento que contribui para a compreensão da politização de imagens no contexto da comunicação global em rede. Se, ao longo desse trabalho, observamos que existem alguns elementos estéticos que aproximam o corpo - entendidos como a "presença", a "realidade", o "testemunho" e a "subjetividade do olhar do amador", a um fazer político por meio das imagens - podemos então admitir que esse potencial político do corpo permanece quando direcionamos nosso olhar para a produção de imagens contemporâneas, já que tratamos aqui de características da recepção humana e como ela pode ser mobilizada politicamente.

Nesse sentido, notamos que a interpretação das imagens como aqui apresentamos pode ser melhor compreendida se observarmos que há nelas uma relação de poder. Um poder que age diretamente sobre os corpos dos indivíduos, o chamado biopoder. Assim, é importante entendermos em que medida as práticas de biopolítica podem estar incentivando tanto a produção de imagens políticas como a sua interpretação no mundo contemporâneo, assim como agiram no passado.

O debate sobre a articulação biopolítica nas imagens contribui, portanto, para entendermos os vínculos com a tradição política das imagens e, ao mesmo tempo, para observarmos como os elementos ligados ao corpo (nas imagens contemporâneas) adquirem conotações maiores se aproximados a instâncias de poder que agem sobre suas produções e recepções. Nesse sentido, a interpretação de imagens de cunho 
ativista, realizadas por amadores (ou testemunhas oculares) e com ampla presença nas redes de comunicação digital, pode ser melhor realizada se observada sob essa óptica.

\section{REFERÊNCIAS}

ANDÉN-PAPADOPOULOS, Kari. The Abu Ghraib torture photographs: News frames, visual culture, and the power of images. In: Journalism, v. 9, n. 1, pp. 5-30, 2008.

BARTHES, Roland. A Câmera Clara. Rio de Janeiro: Nova Fronteira, 1984.

CAPA, Robert. Ligeiramente fora de foco. São Paulo: Cosac Naify, 2010.

DEBORD, Guy. A sociedade do espetáculo. Rio de Janeiro: Contraponto, 1997.

GIROUX, Henry A. Beyond the spectacle of terrorism - rethinking politics in the society of the image. Situations, v. 2, n. 1, pp. 17-51, 2007. Disponivel em: <http://dev.ojs.gc.cuny.edu/index.php/situations/article/ view/153/205>. Acesso em: 01 out 2013.

GUERIN, Frances. The energy of disappearing: problems of recycling Nazi amateur film footage. Screening the past, n. 17, 2004. Disponível em: <http://tlweb.latrobe.edu.au/humanities/screeningthepast/firstrelease/ fr_17/FGfr17.html>. Acesso em: 01 out. 2013.

HÜPPAUF, Bernd. Emptying the Gaze: Framing Violence through the Viewfinder. In: New German Critique, n. 72, 1997, pp. 3-44.

SONTAG, Susan. Diante da dor dos outros. São Paulo: Cia. das Letras, 2003.

\section{NOTAS}

1 "The desire to maintain a space for the self that remains unaffected by the documented horrors creates the necessity of emptying the gaze by desensitizing and de-corporealizing it. Pain and agony are relegated to the other side of the binary divide and subjected to a gaze of abstraction"(Tradução própria).

2 "The amateur colour films become the sites of displaced fear and anxiety. The images themselves are forgotten, their importance and all we have to learn from them is ignored. Similarly, their reach beyond Nazi ideology is rendered irrelevant" (Tradução própria).

3 Um dos materiais que mais mostram as imagens produzidas por bombeiros e policiais é o documentário 9/11 (EUA, 2002, direção de Jules e Gedeon Naudet, e James Hanlon, bombeiro da cidade de Nova York). O cinegrafista acompanha os trabalhos desses profissionais, mostrando imagens de dentro das torres pouco antes de desabarem e até mesmo durante o desabamento. Como consequências, temos imagens 
estarrecedoras que nivelam a grandiosidade do evento para o nível humano, mostrando a tensão dos profissionais e o pavor das pessoas que saiam às pressas dos prédios.

4 "The distinctive mark of the gruesome and horrible attacks on the Twin Towers and the Pentagon is that they were designed to be visible, designed to be spectacular. They not only bear an eerie similarity to violence-saturated Hollywood disaster films but are similarly suited to - intended for - endless instant replay on the nightly news, bringing an end to democratic freedoms with democracy's blessings" (Tradução própria).

5 9/11... and the elevator music in the WTC Plaza played on. Disponível em: < http://tu.tv/videos/and-the-elevatormusic-in-the-wtc-plaza >. Acesso em: 01 out 2013.

6 Hoje sabemos que esta foto foi encenada. Mesmo assim, ainda está fortemente presente na memória mundial como um símbolo do início da vitória dos aliados na II Guerra Mundial ou ainda do domínio americano sobre o território japonês e, consequentemente, a superioridade de um país sobre o outro.

7 "The economic, political, and social safeguards of modernity, however restricted, along with traditional spatial and temporal coordinates of experience, have been blown apart in the "second media age" as the spectacularization of fear and the increasing militarization of everyday life have become the principal cultural experiences shaping identities, values, and social relations" (Tradução própria).

8 "Images which contradict or disrupt a dominant discursive frame might have a considerable impact, if not directly on politics and policy-making, then more so on popular imagination and historical consciousness. Iconic news media images are notorious migratory, often being instantly appropriated and re-circulated in the wilder culture" (Tradução própria).

Recebido em: 01 out. 2013

Aceito em: 07 mar. 2014

\section{Endereço do autor:}

Tarcisio Torres Silva <tarcisio.silva@puc-campinas.edu.br> Pontifícia Universidade Católica de Campinas - PUCCAMP

Rodovia Dom Pedro I, Km 136 - Parque das Universidades 13086-900 Campinas, SP, Brasil 